\title{
Emotional interplay and communication with patients diagnosed with schizophrenia
}

Helena Fatouros Bergman 


\begin{abstract}
Emotional interplay and communication with patients diagnosed with schizophrenia was studied in clinical interviews. Fifty-one video recorded interviews were conducted by two psychologists with nine patients. Qualitative and quantitative methods were used in three successive studies. Study I examined the communicative interplay on an overall level, including verbal and nonverbal means of communication. The interviewer's willingness to explore and pursue the emotional content in the patient's narrative was found to be important for establishing well functioning communication. In Study II, the stability over time of facial affective expressions in the emotional interplay was evaluated, using EMFACS. For the patients, no substantial changes in the amount of affects were found across all the interview occasions, although for one interviewer, contempt slightly increased. Whereas previous findings found contempt to be the most frequent affect in patients, in the present material disgust was as common, but depended on the interviewer. Study III investigated gaze behaviour and facial affective expressiveness. The objective was to test whether patients reduced their negative facial affectivity during mutual gaze. The patients were found to not reduce their negative facial affectivity during the state of mutual gaze. This finding was independent of both interview occasion and interviewer and implies that the patients might have intended to communicate negative facial affectivity to the interviewer. The research suggests that the emotional interplay is dominated by the negative facial affective expressions of mainly disgust and contempt. It is proposed that these negative affects may be connected to a patient's low self-esteem, as the self in schizophrenia may be engrained by self-disgusting and self-contemptive affective experiences. The interviewer's capacity to respond to these negative facial expressions must therefore be considered as important.
\end{abstract}

Key words: Schizophrenia, communication, affects, EMFACS, gaze, video observation, nonverbal. 


\section{LIST OF STUDIES}

The present thesis is based on the following papers:

I. Fatouros Bergman, H., Preisler, G., \& Werbart, A. (2006). Communicating with patients with schizophrenia: Characteristics of well functioning and poorly functioning communication. Qualitative Research in Psychology, 3, 121-146.

II. Fatouros Bergman, H., Sprang, J., Merten, J., Preisler, G., \& Werbart, A. Stability over time of facial affective expressiveness in clinical interviews with patients diagnosed with schizophrenia. (Submitted.)

III. Fatouros Bergman, H., Sprang, J., Werbart, A., Preisler, G., \& Merten, J. The interplay of gaze behaviour and facial affectivity in clinical interviews with patients diagnosed with schizophrenia. (Submitted.)

Paper 1 is reprinted with permission from the Qualitative Research in Psychology, (c) 2006 Routledge. 


\section{CONTENTS}

$\begin{array}{lr}\text { INTRODUCTION } & 1\end{array}$

Interpersonal communication $\quad 1$

The diagnosis of schizophrenia 8

Disorganised speech in schizophrenia $\quad 11$

Gaze behaviour in schizophrenia $\quad 11$

Facial affective expressions in schizophrenia 12

The facial affective expression of contempt and disgust 13

The impact of patient's facial affective behaviour on healthy subjects

Interpretation of facial affective behaviour 15

The influence of antipsychotic medication on facial

expressiveness

Objectives

METHODS

Methodological considerations

Ontology and epistemology in qualitative and quantitative research

Procedures in qualitative and quantitative research $\quad 20$

Inductive and deductive approaches

Validity and generalisability in qualitative and

quantitative research

Advantages and limitations of qualitative and

quantitative methods

Subjects

The interviews

24

Video recording

26

Interviews and sequence selection $\quad 27$

Qualitative methods 28

Quantitative methods $\quad 30$

Statistics 31

Ethical aspects 31

SUMMARY OF THE STUDIES

$\begin{array}{ll}\text { Study I } & 33\end{array}$

Aim and methods 33

Results $\quad 33$

Conclusions $\quad 34$

Study II 34

Aim and methods $\quad 34$

Results 34

Conclusions $\quad 35$

Study III $\quad 36$

Aim and methods $\quad 36$

Results 36

$\begin{array}{ll}\text { Conclusions } & 37\end{array}$

$\begin{array}{ll}\text { DISCUSSION } & 38\end{array}$

Main findings and interpretations $\quad 38$

Clinical implications $\quad 41$

Validity and generalisability $\quad 43$

Future research $\quad 48$

Overall conclusions $\quad 48$ 
ORIGINAL PAPERS

PAPER 1. Communicating with patients with schizophrenia:

Characteristics of well functioning and poorly functioning communication

PAPER 2. Stability over time of facial affective expressiveness in clinical interviews with patients diagnosed with schizophrenia

PAPER 3. The interplay of gaze behaviour and facial affectivity in clinical interviews with patients diagnosed with schizophrenia 



\section{INTRODUCTION}

This project is a detailed study of the communicative and emotional interplay with patients with schizophrenia in clinical interview situations. The overall aim is to improve communication with this group of patients.

First the foundations of communication in general are given. Next the diagnosis of schizophrenia is described with a focus on specific characteristics of these patients' communication, which leads the reader to the objectives of this dissertation.

\section{Interpersonal communication}

Infants have a readiness for communicating from the beginning of life (Trevarthen, 2004; Trevarthen \& Marwick, 1986). This ability to interact with and to attach to another human being is crucial for the infant's survival and might therefore serve evolutionary purposes (Trevarthen, 2004).

New technologies developed during the last decades have made it possible to study communication between infants and caregivers in a very detailed manner (Butterworth \& Cochran, 1980; Stern, 2000; Trevarthen, 1990, 1993, 2004; Tronick, 1998, 2007). From birth, infants have been found to be able to enter into an exchange of feelings and act communicatively with the caregiver. Eye contact is sought. Movements of eyes and mouth, hand gestures, and vocalizations can be imitated by the infant (Kugiumutzakis, 1998; Meltzoff, 1986; Nadel, Guérini, Pezé \& Rivet, 1999). 
Recent research has indicated that there is a physiological predisposition in infants to imitate others' behaviour from birth, and more importantly, to comprehend another person's motives (Trevarthen, 2004). How this process can be obtained has now been explained in terms of a neuron system in the cortex. This was first observed in chimpanzees (Rizzolatti \& Arbib, 1998), but has later been found in humans as well (Rizzolatti, Craighero \& Fadiga, 2002). Neurons in the brain have been found to discharge during active movements of the hands and mouth, both in the person performing the actions as well as the person observing the actor. This firing in the brain is now considered to explain how we can understand other person's actions. Rizzolatti and his co-workers called these neurons "mirror neurons". Trevarthen (2004) maintains that the firing of mirror neurons exists in a widely distributed system of the brain concerned with the possibility to feel, not only to move, with another. The mirror neuron system enables us to read others' communicative behaviours and to understand others' emotions and intentions. These capacities have enabled humans to develop and understand symbols and to produce gestures and speech (Volterra, Caselli, Capirci \& Pizzuto, 2005).

When the infant is between one and two months old, the infant and the caregiver start to communicate by means of cooing, vocalizations, eye contact, smiles and body movements in dialogue-like exchanges (Trevarthen \& Aitken, 2001). Communication in these early interactions is often described in terms of mutuality, reciprocity, timing, turn-taking, coordination and congruence. These are qualities of importance in early communication and continue to play a role even after the person is able to communicate verbally (Stern, 2000). 
An important prerequisite for this early communicative interplay is the sharing of a common focus of attention. Initially, gaze plays a monitoring role in achieving a mutual focus of attention (Butterworth \& Cochran, 1980; Butterworth \& Jarret, 1991; D’Entremont, Hains \& Muir, 1997; Hood, Willen \& Driver, 1998). As the infant grows older, pointing will play a similar role (Butterworth \& Morissette, 1996; Pizzuto \& Copabianco, 2005).

Caregivers give meaning to the infant's expressions and react to the infants' actions as if they were intentional (Goldin-Meadow, 1998). They imitate and mirror the expressions as well as their affective content by verbal and nonverbal communication. This process is called affect attunement and is a highly synchronised interaction process between the infant and the caregiver (Stern, 2000).

There are, according to Stern (2000), three general features of behaviours that form the basis of attunement. These are intensity, timing and shape. The loudness of a caregiver's voice can match the force of the infant's body movements, and the temporal beat of the movement of the caregiver can match the behaviour of the infant. Finally, the form of the infant's movement can be abstracted and rendered in a different act by the caregiver. These ways of sharing affect are among the most important features of inter-subjective relatedness. Vitality affects, captured in kinetic terms such as fading away, fleeting, accelerating, drawing out and hesitating, are important parts of early communication as they are a way of illustrating affects and emotional nuances through different movements or shifts in tempo (Stern, 2004). Schore (1994) claims that affective exchanges within an attachment relationship in infancy constitute the core of the self. He further maintains that the core self in infancy is nonverbal 
and constituted through patterns of affect regulation with the caregiver. The caregiver regulates overwhelming affective states, as the infant not yet is capable of autonomously regulating affects.

In these early interactions, nonverbal means of communication play an important role. Nonverbal means continue to be an essential part of communication even in adulthood, and we use gestures, facial expressions, gaze behaviour, body movements and body postures to convey messages (Bavelas, Coates \& Johnson, 2002; Ekman 1993, 1997; Ekman \& Davidson, 1997; Kendon, 1967, 1972, 1980, 1981, 1995; McNeill, 1992; Scheflen, 1978). The way we talk, so-called "paralinguistic features"; i.e. tempo, rhythm, pitch, loudness, syllabic duration, intonation etc. are also important aspects of communication (Poyatos 1993, 2002).

In order for the infant to create a coherent perception of a situation, the content of verbal messages, the gestures, the tone of the voice, as well as the facial expressions have to fit each other in a coherent manner (Field, 1994; van Egeren, Barratt \& Roach, 2001). For example, infants can recognize and prefer when speech and lip movements are synchronised (Dodd, 1979). Usually speech, gesture, facial expression and gaze are coordinated (Bavelas et al., 2002; Condon \& Ogston, 1967; Furuyama, 2002; Kendon, 1967, 1972, 1980; Kita \& Özyürek, 2003; Rutter \& Durkin, 1987). But, when verbal information contradicts information that is delivered by gestures, listeners still regard the information conveyed by gestures as valid (Cassell, McNeill \& McCullough, 1999).

Efron (1941) was the first to classify gestures, and he described gestures in different ethnic groups in New York City. Based on Efron's observations several types of gestures have been described by Ekman and Friesen 
(1969). Emblems are gestures, usually used intentionally, that correspond to a direct verbal translation and can substitute for verbal utterances. Illustrators are gestures that illustrate speech, for example, movements that emphasize a particular word, movements that describe spatial relationships or the direction of thought during conversation. Regulators, are gestures that regulate turn taking during the conversational flow, they indicate for example that the interaction partner should hurry up, or continue to speak. Finally adaptors are movements that correspond to adaptive efforts to regulate bodily needs during conversation, for example wiping of lips with the tongue (Ekman \& Friesen, 1969). Body movements and postures are also important for communicative interplay and have also been studied in psychotherapy sessions (Scheflen, 1963, 1964, 1978).

Facial expressions constitute another important component in nonverbal behaviour. Darwin (1872/1998) studied the human face as well as the facial expressions of other primates and recognized that several expressions were found repeatedly. He claimed that these expressions were innate and universal to mankind. Tomkins (1962, 1963, 1991), as well as Izard (1994), also claimed that facial expressions were innate and found across different cultures. Tomkins' (1962, 1963, 1991) work “Affect-ImageryConsciousness" was the starting point for affect theory. He described affects as constituting a major system in human functioning, equivalent in importance to both cognition and the drives. He further developed Darwin's observations and distinguished several facial expressions and related them to distinct emotional states. He described the following affects: Interest-Excitement, Enjoyment-Joy, Surprise-Startle, DistressAnguish, Fear-Terror, Shame-Humiliation, Contempt-Disgust, AngerRage. 
Ekman and Izard developed Tomkins' theories further. Together with Friesen, Ekman (Friesen \& Ekman, 1984) has systematically studied facial affective behaviour using video recordings. Ekman and Friesen have described in detail visible muscular facial movements and operationalised seven specific primary affects (anger, contempt, disgust, fear, sadness, surprise and happiness). These affects correspond to Tomkins' descriptions with the exception of shame and interest. They further made a distinction between contempt and disgust. Based on ethnological and ethological research (Ekman, 1985; Hufnagel, Steimer-Krause \& Krause, 1991), and in agreement with Darwin's and Tomkins' claims, these affects have been found in several different cultures. Research on facial affective behaviour has shown that healthy subjects show a variety of facial affective expressions, and their most frequent affect is usually happiness (Merten \& Krause, 2003).

In the present dissertation the term affect corresponds to the visible facial expression. The term emotion is broader. Ekman (1997) describes emotions as involuntary expressions of internal states that are mostly not regarded as intentional. Izard (2007) gives the following elaborated description of emotions:

"A basic emotion may be viewed as a set of neural, bodily/expressive, and feeling/motivational components generated rapidly, automatically, and nonconsciously when ongoing affective-cognitive processes interact with the sensing or perception of an ecologically valid stimulus to activate evolutionarily adapted neurobiological and mental processes.” (p. 261-262) 
Izard et al. (1995) showed that emotional expressions are present very early in the facial expressions of infants. He maintained that emotions are a separate system that can operate independently of cognitions (Izard, 1992). Accordingly, emotions act as motivations and result in coping and adaptation strategies. Izard (1992) gives the following examples: the emotion of sadness may motivate generosity and sharing, disgust may result in avoidance of contamination, anger in defensive behaviour and fear in protective behaviours (Barnett, King \& Howard, 1979; Berkowitz, 1990; Bowlby, 1973; Rozin \& Fallon, 1987).

Gaze behaviour is another important part of the communicative interplay. Regarding the coordination of speech and gaze behaviour in dialogues, specific patterns have been found. Typically, the speaker looks less at the listener than the other way around (Bavelas et al., 2002; Duncan \& Fiske, 1977). Usually the person who starts to speak establishes eye contact with the listener, then looks away while starting to speak, and then seeks regular responses by looking at the listener, who usually looks back and hums or nods (Bavelas et al., 2002; Kendon, 1967; Rutter \& Durkin, 1987).

Most studies of gaze behaviour focus on the amount of gaze behaviour and not on the significance and the meaning of gaze in interpersonal communication. Mutual gaze is associated with honesty, love and empathy (Webbink, 1986) and has been found to be connected to the level of intimacy between the interaction partners, since people who like each other gaze more often at each other (Exline \& Winters, 1965). Ethological research states that gaze avoidance can be related to submissiveness and to flight-motivated aspects of behaviour (Grant, 1968). 
To sum up, communication is a complex phenomenon, and in addition to verbal information, consists of several different nonverbal communicative features, such as gestures, facial expressions, gaze behaviour and postures, as well as paralinguistic features. Each of these aspects represents a separate field of research. In addition to the verbal content, the present research studies nonverbal means of communication of facial affective behaviour and of gaze behaviour in patients with schizophrenia in interaction with an interviewer.

A description of the symptomatology in schizophrenia, as well as a description of the communication difficulties specific to individuals with schizophrenia, is given below.

\section{The diagnosis of schizophrenia}

At the end of 19th century, Kraepelin (Egidius, 1997) created the diagnosis of "dementia praecox", denoting a group of patients thought to be suffering from a degenerative form of dementia. Bleuler (Egidius, 1997) later renamed the condition schizophrenia and distinguished four main symptoms: autism, ambivalence, flattened affects and impaired associations. Today, the diagnosis includes several subgroups and is described through a classification of symptoms according to DSM-IV (Diagnostic and Statistical Manual of Mental Disorders, 1994). For diagnostic criteria see Table 1. 
A. Characteristic symptoms: Two (or more) of the following, each present for a significant portion of time during a 1-month period (or less if successfully treated):

1. delusions

2. hallucinations

3. disorganized speech (e.g., frequent derailment or incoherence)

4. grossly disorganized or catatonic behaviour

5. negative symptoms, i.e., affective flattening, alogia, or avolition

Note: Only one Criterion A symptom is required if delusions are bizarre or hallucinations consist of a voice keeping up a running commentary on the person's behaviour or thoughts, or two or more voices conversing with each other.

B. Social / occupational dysfunction.

C. Duration: Continuous signs of the disturbance persist for at least 6 months. This 6-month period must include at least 1 month of symptoms (or less if successfully treated) that meet Criterion A (i.e., active-phase symptoms) and may include periods of prodromal or residual symptoms. During these prodromal or residual periods, the signs of the disturbance may be manifested by only negative symptoms or two or more symptoms listed in Criterion A present in an attenuated form (e.g., odd beliefs, unusual perceptual experiences).

D. Schizoaffective and Mood Disorder exclusion.

E. Substance / general medical condition exclusion.

F. Relationship to a Pervasive Developmental Disorder: If there is a history of Autistic Disorder or another Pervasive Developmental Disorder, the additional diagnosis of Schizophrenia is made only if prominent delusions or hallucinations are also present for at least a month (or less if successfully treated).

Schizophrenia can manifest itself in diverse ways in different individuals and therefore subgroups of symptoms have emerged. In 1898, Kraepelin named three subgroups; paranoid, hebephrenic and catatonic (Egidius, 1997). The DSM-IV recognizes five subtypes of schizophrenia (see Table 2). Communication difficulties may occur due to several of these symptoms, and both verbal and nonverbal means of communication seem to be affected in schizophrenia. 
Paranoid type. A type of Schizophrenia in which the following criteria are met:

1. Preoccupation with one or more delusions or frequent auditory hallucinations

2. None of the following is prominent: disorganized speech, disorganized or catatonic behaviour, or flat or inappropriate affect

Disorganized type. A type of Schizophrenia in which the following criteria are met:

1. All of the following are prominent: disorganized speech, disorganized behaviour, flat or inappropriate affect

2. The criteria are not met for Catatonic type

Catatonic type. A type of Schizophrenia in which the clinical picture is dominated by at least two of the following:

1. motoric immobility as evidenced by catalepsy (including waxy flexibility) or stupor

2. excessive motor activity (that is apparently purposeless and not influenced by external stimuli)

3. extreme negativism (an apparently motiveless resistance to all instructions or maintenance of a rigid posture against attempts to be moved) or mutism

4. peculiarities of voluntary movement as evidenced by posturing (voluntary assumption of inappropriate or bizarre postures), stereotyped movements, prominent mannerisms, or prominent grimacing

5. echolalia or echopraxia

Undifferentiated type. A type of Schizophrenia in which symptoms that meet Criterion A are present, but the criteria are not met for the Paranoid, Disorganized, or Catatonic Type.

Residual type. A type of Schizophrenia in which the following criteria are met:

1. Absence of prominent delusions, hallucinations, disorganized speech, and grossly disorganized or catatonic behaviour.

2. There is continuing evidence of the disturbance, as indicated by the presence of negative symptoms or two or more symptoms listed in Criterion A for Schizophrenia, present in an attenuated form (e.g., odd beliefs, unusual perceptual experiences).

Below communication difficulties attributable to disorganised speech in schizophrenia are first described in some detail. This is followed by a description of what is specific for the nonverbal means of communication of facial affective expressions and of gaze behaviour in schizophrenia. 


\section{Disorganised speech in schizophrenia}

Disorganised speech is one symptom that may occur in patients with schizophrenia and its expression includes derailment and incoherent speech. Accordingly, the original topic of conversation disappears and the narrative appears fragmentized, as the patient's associations frequently change focus with no obvious logical explanation (Bleuler, 1911; Hoffman, Stopek \& Andreasen, 1986). In addition to derailment, other typical speech characteristics include illogicality and neologisms, i.e. the patient invents new words with idiosyncratic meanings (Bleuler, 1911; Hoffman et al., 1986). Morice and McNicol (1986) and Morice and Ingram (1983) found that the patients' speech showed reduced syntactic complexity, disfluency and semantically deviant utterances due to disorganisation. Additionally, Ragin and Oltmanns $(1986,1987)$ reported lack of lexical cohesion in the phase of acute psychosis.

\section{Gaze behaviour in schizophrenia}

Formerly, patients with schizophrenia were considered to avoid other peoples' gaze (Laing, 1960; Riemer, 1955). This was interpreted as the patient's desire to avoid relationships (Riemer, 1955); gaze aversion in turn was seen as an expression of fear of other people and their gaze (Laing, 1960). It is unclear, however, whether this is valid.

The option of video recording of an interaction made the detailed study of gaze behaviour possible. Consequently, although some researchers have found gaze avoidance behaviour in these patients (Pansa-Henderson \& Jones, 1982; Troisi, Pasini, Bersani, di Mauro \& Ciani, 1991; Webbink, 1986) others have not (Rutter, 1976, 1978). Rutter $(1976,1978)$ concluded that the gaze avoidance behaviour seen in schizophrenia was a sign of the 
patient's embarrassment in personal conversations. This indicates that the conversational topic is important to the gaze behaviour shown.

Gaze behaviour is not easily investigated, due to the importance of the study setting, which significantly influences the results. In a research review Pansa-Henderson and Jones (1982) concluded that status differences among the subjects, interaction distance, gender, age, personality variables such as extraversion and nurturance needs, as well as the interaction partner's behaviour, are all important factors for the gaze behaviour shown by the patient. There has been a recent dearth in published studies on gaze behaviour in schizophrenia.

\section{Facial affective expressions in schizophrenia}

The major findings considering facial affective expressivity in patients diagnosed with schizophrenia are twofold. Firstly, it was found that these patients showed an overall reduction of mimic and facial affective expressiveness compared to healthy subjects (Aghevli, Blanchard \& Horan, 2003; Krause, Steimer-Krause \& Hufnagel, 1992; Kring \& Earnst, 1999; Kring \& Neale, 1996; Kring, Kerr, Smith \& Neale, 1993; Trémeau et al., 2005; Steimer-Krause, Krause \& Wagner, 1990). Secondly, they were found to show elevated amounts of negative facial affectivity compared to healthy subjects (Krause et al., 1992; Merten \& Krause, 2003; Schwab, Merten \& Krause, 1997; Steimer-Krause et al., 1990). The most frequent affect shown by a subject, or in a sequence, is called the lead-affect (Krause

\& Merten, 1999; Merten \& Krause, 2003). The lead-affect in patients diagnosed with schizophrenia was usually found to be contempt (Krause et al., 1992; Schwab, Merten \& Krause, 1997; Steimer-Krause et al., 1990) and the second most frequent affect was disgust (Steimer-Krause et al., 
1990). For the purpose of this project, these two negative facial affective expressions are described below in some detail.

The facial affective expression of contempt and of disgust The facial affective expression of contempt may involve feelings of superiority as well as disdain for others (Ekman, 2003). The coding of contempt involves tightened lip corners that are slightly raised (Ekman, 2003), see Figure 1.

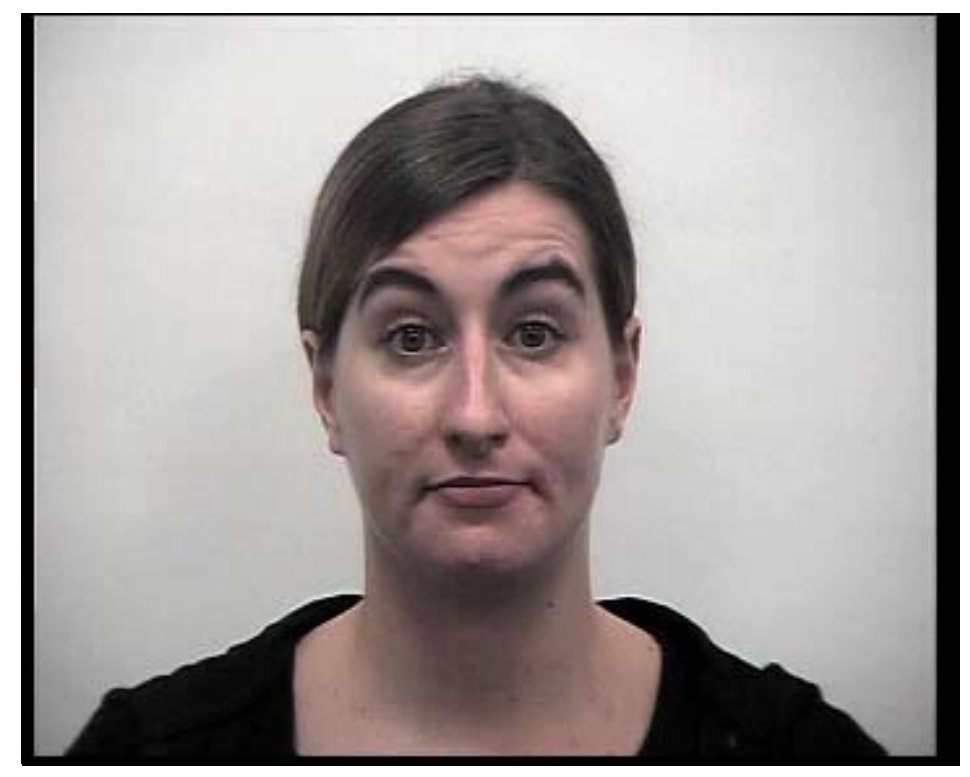

Figure 1. The facial affective expression of contempt

Disgust may be connected to feelings of aversion, often for body products, but may also be evoked by socio-moral violations (Haidt, Rozin, McCauley \& Imada, 1997). The coding of disgust involves the raise of the upper lip and often also nose wrinkling (Ekman, 2003), see Figure 2. 


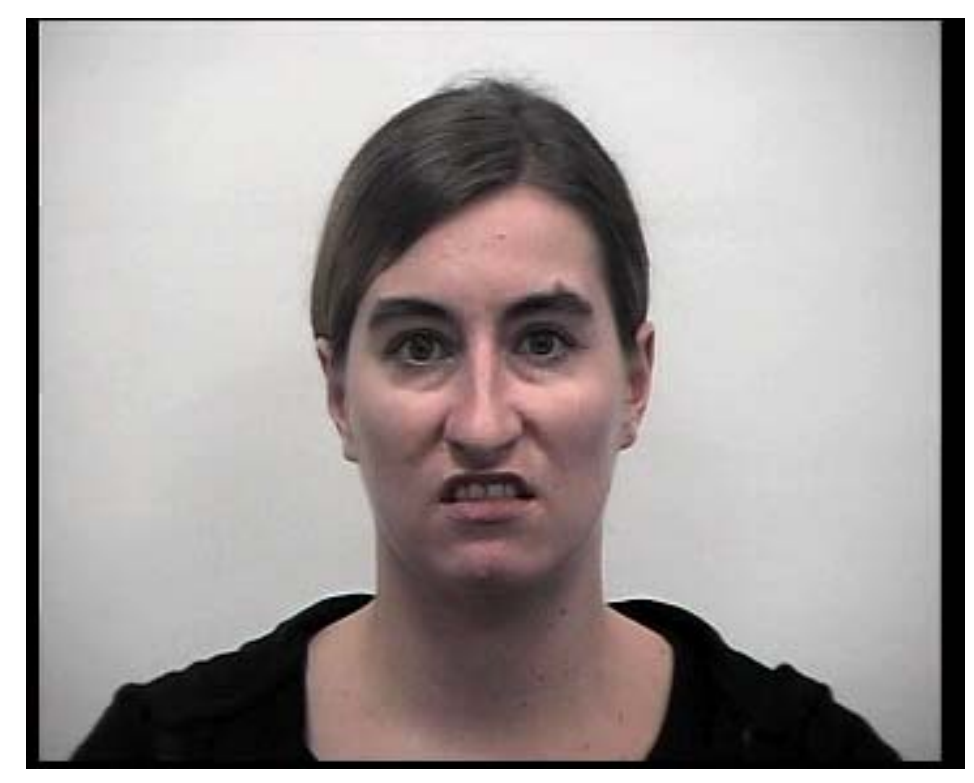

Figure 2. The facial affective expression of disgust

The impact of patient s' facial affective behaviour on healthy subjects

Healthy subjects in interaction with a patient with schizophrenia were found to adjust their facial affective behaviour to resemble that of the patient. They showed fewer affects but elevated amounts of negative facial affectivity, including elevated amounts of contempt (Merten \& Krause, 2003). This correlated with negative psychotherapy outcomes in severely disturbed psychiatric patients. Therapists who managed to maintain variation in their facial affective repertoire were found to have a better psychotherapy outcome (Merten \& Krause, 2003). Their primary facial affective expressions were complementary to the patient's (Anstadt, Merten, Ullrich \& Krause, 1997; Merten, Anstadt, Ullrich, Krause \& Buchheim, 1996). 


\section{Interpretation of facial affective behaviour}

One question of concern regarding facial affective behaviour is whether a facial affective expression should be interpreted as a reflection of the subject's inner emotional state or not. Previous research indicates that depending on the individual's mentalisation capacity and gaze behaviour, facial affective behaviour may reflect several aspects. One possibility is that the facial affective sign reflects the emotional state of the sender, another is that it reflects the emotional quality of the relationship to the interaction partner and the third is that it may function as an illustrator of the affective content in the narrative (Merten, 1997; Merten \& Krause, 2003). In order to decide which alternative is most likely in a specific situation, gaze behaviour and mentalisation capacity must be examined.

In general, research findings (Merten, 1996, 1997) imply that affects expressed during mutual gaze may mostly be considered as an expression of the sender's inner emotional state, or regarded as an illustration of the emotional quality of the relationship to the interaction partner. On the other hand, affects expressed without looking toward the listener are often attributed as illustrations of the affective components of the narrative.

Mentalising entails the capacity to perceive and interpret the behaviour of oneself and others in terms of intentional mental states such as needs, desires, feelings, beliefs, goals, purposes and reasons (Allen, Fonagy \& Bateman, 2008; Fonagy, Gergley, Jurist \& Target, 2002). Individuals with high mentalisation capacity are believed to have a better capacity to relate facial affective expressions to the content of the narrative. Mentalisation is thought to be impaired in schizophrenia (Allen \& Fonagy, 2006; BaronCohen, 1995; Büne, 2005; Frith \& Frith, 2003), and therefore their facial 
affective behaviour is believed to more often reflect their emotional state (Hufnagel et al., 1991; Merten, 1996).

Patients diagnosed with schizophrenia have been found to show reduced amounts of negative facial affectivity of anger, contempt and disgust during mutual gaze in everyday conversations with non-professionals (Merten, 1997). This is thought to be a consequence of their tendency to regard facial affective behaviour as a reflection of inner emotional states or as a reflection of emotions for the interaction partner.

\section{The influence of antipsychotic medication on facial expressiveness}

Many studies concerning facial expressiveness in schizophrenia include patients with ongoing medication, and the question of whether antipsychotic drugs may have an influence on facial affectivity and facial expressivity is therefore important. Mainly, the question is whether antipsychotic drugs contribute to the reduction of the overall facial expressiveness.

Some researchers have found a reduction of facial expressiveness in schizophrenia that was independent of the influence of either typical or atypical antipsychotic medication (Kring \& Earnst, 1999; Trémeau et al., 2005). Significantly fewer outward facial displays of emotions were also observed in non-medicated patients with schizophrenia compared to controls (Kring et al., 1993). These findings indicate that there is a reduction of facial expressiveness in schizophrenia independent of the influence of antipsychotic drugs. 
Other studies have shown that the reduction of facial expressiveness was elevated in medicated patients with schizophrenia compared to unmedicated (Schneider et al., 1992). The conclusions are therefore contradictory. The results may depend on the type of antipsychotic medication as well as dosage. Typical antipsychotic drugs, as for example haloperidol, zuclopenthixol and perphenazine are more prone to have extrapyramidal side effects, such as parkinsonism. These neurological side effects have an impact on the patient's motor activity and contribute to muscular rigidity (Meltzer, 2003). These substances may therefore potentially contribute to a reduction of facial expressiveness. Another extra-pyramidal side effect of antipsychotic medication is tardive dyskinesia, which has an impact on the facial mimic by inducing involuntary movements, primary of the mouth and tongue. This side effect is relative unusual and appears often after many years of antipsychotic medication. Atypical antipsychotic medication, such as olanzapine and ziprosidone, are less prone to give extra-pyramidal side effects. More research is needed before conclusive statements can be made about the influence of antipsychotic medication on facial affective behaviour. However, it is possible that the amount of facial affective behaviour in the patients could be reduced due to medication, but it does not seem reasonable to assume that antipsychotic medication change the quality of the facial affective expressions shown.

\section{Objectives}

The project's objective was to study the emotional interplay and communication between patients diagnosed with schizophrenia and interviewers in series of clinical interviews. Communication was regarded as a process involving both the patient and the interviewer. Both verbal and 
nonverbal means of communication have been studied. Video-recorded clinical interviews with patients with schizophrenia have been used as the source of data.

The dissertation consists of three studies with threefold aims. The first (Study I) was to study the communicative interplay on an overall level, including verbal and nonverbal means of communication. The questions posed were: Can sequences of well functioning and of poorly functioning communication be distinguished? If so, what characterizes these sequences?

The second aim (Study II) was to study the emotional interplay and the stability over time of facial affective expressions. It was hypothesised that the patient's and the interviewer's lead-affects would be negative across all interviews; that there would be no substantial changes in the amount of affects displayed across all the interviews and finally that the patient's affects would not be altered due to the change of interview partner.

The third aim (Study III) was to study gaze behaviour and facial affective expressiveness. It was first hypothesised that the distribution of gaze behaviour would be stable for both the patient and the interviewer across all the interviews. It was additionally hypothesised that both the gaze distribution and the affects displayed by the patients during the different gaze states should be unaffected by the change of interviewer. Previous research has shown that patients diagnosed with schizophrenia in everyday conversations reduced their negative facial affectivity during mutual gaze. Another objective was therefore to confirm this finding in clinical interview series and to test whether it was stable over time and robust to interviewer change. 


\section{METHODS}

\section{Methodological considerations}

In this project both qualitative and quantitative methods were used. The difference in epistemology between these two research approaches affects the research design, the data collection, the analysis, the presentation of the results, as well as questions of validity and generalisability. Therefore, the specific epistemological assumptions that underpin qualitative and quantitative methods have been examined below.

\section{Ontology and epistemology in qualitative and quantitative research}

Qualitative knowledge concerns subjective human experience. Qualitative researchers often stand close to the constructionism tradition, which emphasizes reality as a construction and the studied phenomenon as dependent on our perceptions and experiences of it (Allwood \& Erikson, 1999; McLeod, 2001). Knowledge is often seen as perspectivistic, as it depends on the researcher's perspectives and viewpoints and may therefore vary between different researchers. This way of thinking about knowledge is often referred to as a postmodern approach (Kvale, 1996).

Most researchers representing a quantitative paradigm advocate the ontological standpoint of critical realism, which implies a reality independent of our experiences (Allwood \& Erikson, 1999). However, reality is not thought to be directly accessible, as our assumptions and precognitions about the world may be an intermediating bias. However, through the systematic use of research methods, valid, reliable knowledge 
can be produced (Allwood \& Erikson, 1999). Researchers are expected to obtain roughly the same results under the same conditions and thereby be able to replicate each other's findings (McBurney, 1994).

\section{Procedures in qualitative and quantitative research}

There are several qualitative methods that are predominantly used in psychological research, including hermeneutics, phenomenology and grounded theory. They share in common an aim to understand and create new meanings about human experience. Usually data are narratives, often interviews. In a postmodern approach the creation of data is often seen as a joint construction, which means that the meaning in the interview is not constructed solely by the interviewee. The interviewer, too, is seen to affect the interview (Holloway \& Jefferson, 2000; Kvale, 1996). Therefore data in qualitative research are often regarded as inter-subjective (Frosh, 2001; Kvale, 1996, 2001). The results of qualitative research are predominately narrative descriptions, illustrated with citations and intended to communicate human experience.

Quantitative research, on the other hand, usually aims for objective and controlled measurements and to discover regularities and causal relationships among variables (McBurney, 1994). The conditions under which data are collected are therefore standardized, for example through creating an experimental setting (McBurney, 1994). However, depending on the object of study, experimental settings are not always attainable and therefore other types of designs, such as quasi-experimental and naturalistic, are used (Robson, 2002; Shadish, Cook \& Campbell, 2002). Repeated measurements over time, the use of a control group as well as manipulation of an independent variable are procedures used in order to 
create research designs that permit conclusions of causal inference (Robson, 2002; Shadish et al., 2002).

\section{Inductive and deductive approaches}

In qualitative research the researcher often sets aside pre-existing theories and pre-conceptions in order to approach the material openly. Observations and data coding are frequently explorative. Consequently, conclusions and new theory emerge gradually (Glaser, 1978, 1992; Karlsson, 1995). In qualitative research previous knowledge and pre-conceptions are called pre-understanding.

Quantitative research generally follows a deductive approach (Leahey, 2000). The researcher deduces predictions based on theory and formulates them as hypotheses. These hypotheses are tested, and if not falsified they give support to the theory. The theories are regarded as provisionally true until new findings arise that contradict the assumptions that underpin the theory, which is then revised. Ad-hoc analysis of data and running statistical analysis without pre-defined theories are treated with caution, due to the risk of finding non-accurate correlations due to Type-I errors (Howell, 2002).

\section{Validity and generalisability in qualitative and quantitative research}

In qualitative research the samples are often small and non-random, and there is usually no knowledge about their representativeness. As the aim is to describe many perspectives and nuances, the samples are often chosen to include as much experience diversity as possible (Kvale, 1996; McLeod, 
2001). The individuals constituting a sample are often selected gradually until the data is saturated, e.g. when no new results emerge from the analysis, which is often done parallel to the data collection (Kvale, 1996; McLeod, 2001). The notion of generalisability in this context denotes the ability to apply the results to other situations similar to those that generated the original results (Kvale, 1996, 2001). However, it is not possible to generalise the results to a population. For example, the results from a study about the experience of being unemployed could serve as a description of possible ways of experience unemployment, which some people, but not others, could entirely or partly identify with. Generalisation in this sense is more about being able to communicate experiences that are meaningful and make sense to the reader. Some researchers maintain that the potential readers of an article are those most suitable to define the generalisability of the results on the basis of how well they fit their own experiences (Kvale, 1996).

Validity in qualitative research can be defined as the accuracy of interpretations and conclusions. Perspectivistic knowledge implies many alternative interpretations leading to several different conclusions about data (Kvale, 1996; McLeod \& Balamoutsou, 2001). However, not all possible interpretations are valid. Kvale (1996) refers to distorted subjectivity and to perspectivistic subjectivity. Distorted subjectivity implies that the researcher does not relate to the data in an open way. Instead, only the aspects of the data that support already established theories and pre-conceptions are noticed and contradicting facts are ignored. In contrast, perspectivistic subjectivity signifies an open and critical approach to the data, where the researcher observes data from different perspectives and asks questions leading to various possible interpretations (Kvale, 1996; Malterud, 2001; Rennie \& Frommer, 2001). 
Both the perspectives acting as the starting point for interpretations, as well as the questions put to the material are often openly presented in order to evaluate the validity of the conclusions (Elliott, Fischer, Rennie, 1999; Kvale, 1996).

Self-reflection over pre-understandings and the researcher's impact on both data collection and analysis are seen as important determinants of validity in qualitative research (Frommer \& Rennie, 2001; Holloway \& Jefferson, 2000; Malterud, 2001; McLeod, 2001). Co-raters are sometimes used to enhance validity (Holloway \& Jefferson, 2000; McLeod \& Balamoutsou, 2001). The co-raters have a dialog about the reasonableness of the interpretations (Karlsson, 1995; Riquouer, 1971), critically examine the analysis and counteract selective perception of data (Kvale, 1996). They strive to approach inter-subjective agreement with conclusions built on logical arguments showing coherence and lack of inconsistency (Elliott, Fischer, Rennie, 1999; Hill et al., 2005; Kvale, 1996; Ödman, 1994). Finally, in qualitative research the results are usually illustrated by interview quotes, in order to give the reader the opportunity to estimate conclusion reasonableness and validity (Kvale, 1996; Morrow, 2005).

In quantitative research, the ability to generalise the findings builds on the notions of randomisation and large samples from a population. Proper use of random samples maximizes the chance that these samples are representative of the population as a whole, thereby allowing generalisation of the results to the population. The confidence interval for generalising about a randomly selected sample to a population can be determined by inferential statistics and stated as probability coefficients (Howell, 2002). To obtain good generalisability, a probability (i.e. power) is often 
calculated to determine a required sample size for being able detect a specified effect if it truly exists (Howell, 2002).

In quantitative research, validity denotes measurement precision as well as data collection free from systematic bias (Shadish et al., 2002). For example, in experimental research randomisation is used to allocate subjects to equally representative groups so that the causal inference is due to experimental effects and not due to original group differences. Among other aspects, measurement precision relies on how well theoretical constructs are operationalised, as well as on the adequacy of the instruments used to measure these constructs (Shadish et al., 2002).

\section{Advantages and limitations of qualitative and quantitative methods}

Qualitative research has the advantage of discerning individual differences and nuances and enables detailed descriptions of the studied phenomenon. The emphasis is on in-depth understanding. On the other hand, quantitative research permits generalisation of research results to populations, although individual nuances are lost as the focus is usually on means and group differences. However, these two approaches can be complementary, since quantitative results can be followed up through qualitative research, or qualitative results may be used to generate hypotheses (Allwood, 1999; Maxwell, 1996). 


\section{Procedures}

\section{Subjects}

All the patients in the present research project came from the same psychiatric clinic. A total of 25 patients diagnosed with schizophrenia (DSM-IV, 1994) were asked to participate in series of video-recorded interviews by the staff at the clinic. Nine agreed to do so. Detailed subject characteristics for those who declined participation were not available. Data were collected two years apart. A first series of interviews was conducted in 2001 (data set 1) by myself (interviewer 1), and a second series of interviews was conducted in 2003 (data set 2) by another interviewer (interviewer 2) (see Figure 3).

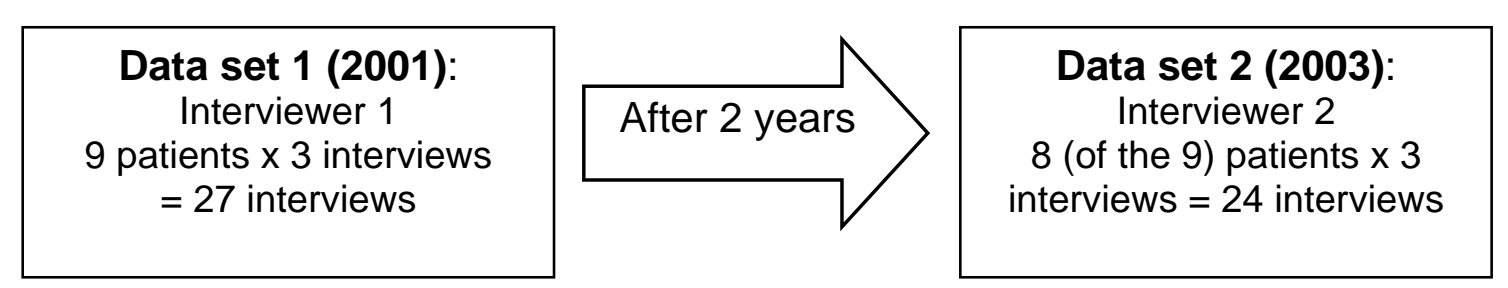

Figure 3. Data collection

The same patients participated both times, with the exception of one patient who did not participate in the second interview series due to a change of residence. One patient was re-diagnosed as having delusional disorder prior to the second data collection, but remained in the study. All interviews were conducted in the same room at the psychiatric clinic. Table 3 presents the characteristics of the patients at baseline. 
Table 3. Patient characteristics in 2001

\begin{tabular}{lccclll}
\hline Gender & Age & $\begin{array}{l}\text { Psychosis } \\
\text { diagnosed }\end{array}$ & $\begin{array}{l}\text { Schizophrenia } \\
\text { diagnosed }\end{array}$ & $\begin{array}{l}\text { Type of } \\
\text { schizophrenia }\end{array}$ & $\begin{array}{l}\text { Type of } \\
\text { medication } \\
2001\end{array}$ & $\begin{array}{l}\text { Type of } \\
\text { medication } \\
2003\end{array}$ \\
\hline F & 27 & 1993 & 1993 & Paranoid & $\begin{array}{l}\text { Clozapine } \\
\text { Raranoid (2003: }\end{array}$ & $\begin{array}{l}\text { Data missing } \\
\text { Risperidone }\end{array}$ \\
M & 27 & 1992 & 1997 & $\begin{array}{l}\text { Relusional disorder) } \\
\text { Pidone }\end{array}$ \\
M & 40 & 1987 & 1989 & Paranoid & Olanzapine & Risperidone \\
M & 32 & 1991 & 2000 & Undifferentiated & Perphenazine & Perphenazine \\
M & 52 & 1967 & 1971 & Paranoid & Zuclopenthixol & Zuclopenthixol \\
M & 36 & 1994 & 1994 & Paranoid & Olanzapine & Olanzapine \\
F & 48 & 1985 & 1985 & Paranoid & Zuclopenthixol & Zuclopenthixol \\
F & 52 & 1972 & 1982 & Paranoid & Ziprasidone & None \\
M & 27 & 1998 & 1998 & Catatonic & Olanzapine & Olanzapine \\
\hline
\end{tabular}

Both age and duration of illness varied. Some were between 40 and 52 years old, had a long-standing schizophrenia diagnosis and had several inpatient psychiatric care admissions. Others were between 27 and 36 years old, had more recent diagnoses and only one or two psychiatric ward admissions. Each patient was either retired or unemployed. None had problems with substance abuse nor been diagnosed with brain damage, and none was in a state of acute psychosis during the interviews. Most were taking same type of antipsychotic medication at both data collection periods.

\section{The interviews}

Both data collection series were conducted identically and were similar to interviews used in clinical situations. Each interview series comprised three interviews, labelled $A_{1}, B_{1}$ and $C_{1}$ for data set 1 and $A_{2}, B_{2}$ and $C_{2}$ for data set 2. An open interview model focusing on the patient's own descriptions of their problems, background to these problems, as well as ideas of cure, was used as the frame of reference for interviewing (Werbart \& Levander, 2005). The narratives were frequently about psychotic experiences, the 
crisis of the patient's first psychotic episode and other difficult past experiences related to the patient's disorder. Both interviewers were female psychologists with clinical experience with this group of patients and met the patients approximately once a week. In this way a dialogue was established between the patient and the interviewer. They could further maintain the dialogue and explore a subject in depth. Bias due to nervousness and day-specific influences on the interviews could thus be diminished. The interviews were conducted in a manner that promoted mutuality and encouraged the patient to contribute ideas and perspectives. The purpose of the interviews was not to gather information about the patient. Instead, it was considered important to listen to the patients' stories and to let them share their thoughts. Each interview lasted 45 minutes. A total of 51 interviews were conducted. Verbatim transcripts of the interviews included the paralinguistic features of pauses and sighing.

\section{Video recording}

Three visible remote-controlled cameras recorded the interviews. They were installed in the ceiling and steered by a person in another room. The patient and the interviewer sat in armchairs. One camera recorded the interviewer's face, another recorded the patient's face and the third the whole scene showing the participants in full view. The camera uptakes were synchronised and provided with a time code. The interviews were stored on DVD discs and replayed, including slow motion, on a computer screen, by using Power-DVD ${ }^{\circledR}$ version 3.0 software. 


\section{Interviews and sequence selection}

The first study used data set 1 . A co-rater and I independently selected sequences from the 27 interviews for further analysis based on whether communication was considered to be well functioning or poorly functioning. Both verbal and nonverbal means of communication were taken into consideration. The assumption was that we, based on our intuitive knowledge and clinical experience, would be able to choose sequences corresponding to well and poorly functioning communication, in terms of mutuality, reciprocity, turn-taking, timing, congruence, coordination, understanding as well as sharing intention and meaning. Differing opinions about whether sequences should be deemed to be well or poorly functioning were resolved through discussion and consensus was reached through emphasising context as well as the hermeneutical dialogue between the parts and the whole (Hill, et al., 2005; Kvale, 1996; Ricoeur, 1971). Chosen sequences were compared and only highly dissimilar sequences were retained. Finally, 73 sequences were chosen for detailed analysis, corresponding to 3 full hours and contained both well functioning and poorly functioning sequences.

Studies two and three used both data sets. All interviews $\left(A_{2}, B_{2}\right.$ and $\left.C_{2}\right)$ in data set 2 and the first interviews $\left(A_{1}\right)$ in data set 1 were included in the analysis and comprised 32 interviews. Again, a sequence selection was made. The aim was to select sequences that frequently occurred in clinical situations. I selected sequences of psychotic and other exceptional experiences e.g. a patient described how he could hear several harassing voices that nobody else could hear. These narratives tended to be emotionally loaded and therefore considered to trigger facial affective expressivity. The content was often about negative emotions such as fear and mental suffering. Compared to the selection in study I, this was based 
on the content of the narratives and not on judging the communication quality of the interaction. Therefore a co-rater was only engaged initially in the selection process, as the discrepancy between our judgments was negligible. Two 3-minute sequences were selected from each interview, resulting in a total of 64 sequences lasting 3 full hours and retained for further analysis.

\section{Qualitative methods}

To preserve openness in relation to the data in study I, no pre-established categories or coding schemata of interpersonal interaction were used. The analysis was inspired by Kvale’s (1996; 2001) approach to qualitative research as influenced by hermeneutics and postmodernism. The coding procedure in the analysis was based on grounded theory (Glaser, 1978, 1992).

The application of qualitative methods on video data differs from that used on verbal data. Although qualitative analysis typically focuses on understanding human experience, a video observational approach provides no access to the subjects' lived experiences. Instead of asking how people experience communication they are observed while communicating. The conclusions are therefore based on the researcher's observations and interpretations and not on the subject's reporting. Therefore video observational research requires an element of hermeneutic interpretation and includes changing perspectives as well as reflections on preunderstandings in order to draw valid conclusions.

First nonverbal means of communication such as gaze, facial expressions, posture, head and body movements were transcribed from the sequences 
selected for detailed analysis and added to the verbal material. Both verbal and nonverbal communication was coded according to grounded theory procedures. Each patient was entered onto two lists of codes, one for well functioning and one for poorly functioning communication. Another corater and I independently categorised the codes. Differing opinions about conclusions and coherent categorisation were discussed from different perspectives. The analysis ended with a core category having emerged to which other categories were related forming a model of the communication process.

\section{Quantitative methods}

To evaluate the patients' and the interviewers' facial affective behaviour in studies II and III, the Emotion Facial Action Coding System (EMFACS), (Friesen \& Ekman, 1984) was used. Ethnological and ethological studies (Ekman, Sorenson \& Friesen, 1969; Hufnagel et al., 1991) have confirmed this coding system as valid for identifying facial affective expressions. EMFACS is used on visual data, photography and video data, and is based on the Facial Action Coding System (FACS, Ekman \& Friesen, 1978). FACS permits coding, labelled Action Units (AU), of all mimic movements of the face. In order to code the AUs, the interviews were replayed a maximum of three times. If not being able to register the AU after three replays the coder went on to next AU. The onset and the end of the AUs were not coded, instead the AU was coded at its apex, that is when the $\mathrm{AU}$ is most intensely shown. If the intensity of an AU increased or decreased, then a new AU was recorded. The duration of both AUs and of affects is estimated to last milliseconds or seconds. A specific affect in turn is comprised of several AUs. It is found by running all the AUs through an emotional dictionary software. This software compares the different 
combinations of AUs with the EMFACS dictionary and interprets the following seven affects: anger, contempt, disgust, sadness, fear, surprise and happiness. However, most AUs are not part of any affective expression. This procedure of separating the detection of visible facial mimic movements (FACS) from the interpretation (EMFACS), is considered to contribute to a more objective coding of facial affective behaviour. In addition to affects, EMFACS registers, blends, masking and eye movements. Blends are facial expressions containing parts of at least two affects, masking "covers up” negative affects with smiling, and eye movements are information about where the persons look while the affect is displayed. Reliability for EMFACS has been deemed to be excellent (Steimer-Krause et al., 1990).

To achieve valid coding, two independent female coders lacking command of the language spoken in the interviews or knowledge of the patients' diagnoses conducted coding at the University of the Saarland in Saarbrücken, Germany. The same coders also performed the gaze coding in study III.

\section{Statistics}

The SPSS statistical package version 15 was used for all statistical analyses. Data were summarised through descriptive statistics, such as frequency, mean and standard deviation. In order to compare mean differences of facial affectivity across several interview occasions, withinsubjects ANOVA was used. Wilcoxon test for repeated measures was used for comparisons of related samples and a Mann-Whitney test was used on independent samples. 


\section{Ethical aspects}

Use of cameras in research with patients diagnosed with schizophrenia may be questioned from an ethic perspective. Symptomatology in these patients may sometimes include suspiciousness and thoughts about being secretly filmed or watched. Therefore transparency was crucial in the present research. The patients were informed about the focus of the project, but not about the focus on gaze behaviour and facial affectivity, as that may have adventured the validity of the research. However, all information regarding the filming details was made available to the patients. They were shown the equipment and given the opportunity to watch each videotaped interview and delete it if uncomfortable with it. No patient ever exercised this last option.

The patients received an information letter about the project. They were guaranteed anonymity in the research reports. It also explained that declining to participate would not affect their treatment at the clinic. They were also informed that they could end their participation at any stage of the data collection. The patients participated after granting their informed consent. The interviewers had no treatment contact with any of the patients. Only individuals directly involved in the research process were allowed to watch the interview uptakes. The project was approved by the Committee of Ethics of the Örebro County Council, Sweden. 


\section{SUMMARY OF THE STUDIES}

\section{Study I}

\section{Aim and methods}

The first study aimed to explore and describe verbal and nonverbal communication between patients diagnosed with schizophrenia and an interviewer. Data set 1 was used, which encompassed 27 interviews with 9 patients. Selected sequences were analysed using qualitative methodology.

\section{Results}

In well functioning communication the interviewer invited the patient to a dialogue by frequently asking open questions, often about emotionally charged topics. The interviewer recurrently explored the emotional content of the patients' narratives and did not focus on logical inconsistencies when the narrative became incoherent. The interview turned into a dialogue and the patient became more talkative. The interviewer and the patient frequently engaged in mutual gaze. The nonverbal means of the interviewer appeared emotional confirming, as she often leaned toward the patient, sat with her head tilted and eyebrows wrinkled as if concerned, and nodded repeatedly. The patient showed few nonverbal means and appeared calm and relaxed.

Difficulties in establishing well functioning communication were also found. In such sequences the interviewer frequently asked extended questions with abstract terms and embedded statements. The conversation was often fragmented, incoherent and confusing. The interviewer and the patients generally avoided eye contact, and long pauses were frequent. 
Nonverbal means of communication expressed discomfort, and the participants were found to alternately dominate the conversation.

\section{Conclusions}

Emotional interplay seemed important for communication. When the interviewer focused on the emotional aspects of the patient's narrative and asked questions regarding the patients feelings, communication seemed to progress. The interviewer's capacity to contain and to respond to the emotional interplay seems therefore to be significant for establishing well functioning communication.

\section{Study II}

\section{Aim and methods}

The second study examined the stability of facial affective expressions in emotional interplay. All interviews in data set 2 and the first interview $\left(A_{1}\right)$ in data set 1 were used. Sequences corresponding to 3.2 hours concerning exceptional experiences were evaluated by independent coders for both patient and interviewer using EMFACS (Friesen \& Ekman, 1984).

\section{Results}

Facial affectivity in both patient and interviewer was found to be heavily negative, with disgust and contempt predominating. The lead affects for all patients and for the interviewer were negative in all of the interviews. Thus, the first hypothesis, stating that across all interviews, the patient's and the interviewer's lead-affect would be negative, was retained. 
For the patients in data set 2, no substantial changes in the amount of affects displayed across all the three interview occasions were found, which suggest that the affects appear stable and seem fairly independent of interview occasion. For the interviewer, a significant effect was found for contempt, indicating that the amount of the interviewer's contempt increased during the series of the interviews. With that exception, the study's second hypothesis stating that the amount of the patient's and the interviewer's affects should be stable across all the interview occasions was retained.

No significant differences for any of the displayed affects were found when comparing the patients' affects in interaction with both interviewers, except for higher amount of contempt shown to interviewer 1. Thus, the study's third hypothesis, stating that a patient's affects should be invariant to a change in interview partner, was retained.

\section{Conclusions}

Both patients and their interaction partners displayed negative facial affectivity. The patients' amount of affects seemed to be stable over the interview series. However, contempt increased slightly with change of interviewer. Whereas previous findings found contempt to be the most frequent affect in patients with schizophrenia, in the present material disgust was as common, but depended on the interviewer. It was hypothesised that the disgust and contempt present in these patients facial behaviour may be connected to low self-esteem. 


\section{Study III}

\section{Aim and methods}

This study examined the interplay between gaze and facial affective behaviour. The same data as in study II were used. In addition to facial affective behaviour (EMFACS), the independent coders also coded gaze behaviour.

\section{Results}

No substantial changes in the distribution of the four different gaze states, i.e. the amount of time spent looking at, as well as looking away from, the interaction partner in data set 2, were found. This indicates that the distribution of the four different gaze states was stable across the interview occasions. Furthermore, the distribution of gaze behaviour in the first interview $\left(\mathrm{A}_{2}\right)$ in data set 2 was compared to the distribution of gaze behaviour in the first interview $\left(A_{1}\right)$ in data set 1 . No significant differences were seen for any of the gaze states. Thereby the first hypothesis, stating that the distribution of gaze behaviour would be stable for both the patient and the interviewer across all interviews and unaffected by change of interviewer, was retained.

The second hypothesis stated that independent of interviewer and interview occasion the patients would express less negative facial affectivity during mutual gaze than expected by chance. The proportion of each affect shown during mutual gaze, relative to all the expressions of the affect, was compared to the proportion of the overall duration of mutual gaze relative to the total interview time. The results showed that the observed percentages for contempt were as great as would be expected by chance in 
all interviews in both data sets. Disgust and anger were expressed as often as would be expected by chance in data set 1 , but not in all interviews in data set 2 . However, when these three affects were aggregated into a generic "negative affect" component, they were displayed as often as would be expected by chance during mutual gaze in both data sets. The second hypothesis was therefore rejected.

Comparing A interviews in data set 1 and 2 showed no significant difference for any of the affects shown by the patients in the different gaze states. Thus, the third hypothesis which stated that the patients' affects shown during each gaze state were not altered by the change of interview partner, was retained.

\section{Conclusions}

The type of interview was found to be important for the amount of mutual gaze that the participants engaged in, as well as for the amount of negative facial affectivity expressed during mutual gaze. In clinical interviews, such as those in the present study, a higher amount of negative facial affectivity was shown during mutual gaze compared to everyday conversations with non-professionals, such as was examined in previous research. Higher amount of mutual gaze per se was also observed in the clinical interviews. It was concluded that the patients were more prone to communicate and share negative facial affectivity in clinical interviews. The professionals' capacity to be open for and able to handle the negative emotions that the patient might want to share is therefore emphasized. 


\section{DISCUSSION}

\section{Main findings and interpretations}

The present research project studied the emotional interplay and communication with patients diagnosed with schizophrenia while focusing on collecting detailed information on interactions in clinical situations. New information was found about how these patients communicate and interact emotionally with a professional.

In addition, previous findings about emotional interplay in schizophrenia was confirmed concerning elevated amounts of negative facial affectivity in the emotional interplay with patients with schizophrenia (Krause et al., 1992; Merten \& Krause, 2003). Both contempt (Krause et al., 1992; Schwab et al., 1997; Steimer-Krause et al., 1990) and disgust (SteimerKrause et al., 1990) were found to be frequent affects. However, no previous research had examined the robustness of these findings, nor whether they are present in clinical situations with these patients.

Negative facial affectivity in patients diagnosed with schizophrenia was found to be a stable and prominent feature. The negative facial affective expressions of disgust and contempt dominated both the patients' and interviewers expressions. This finding is stable and appears robust.

A variation of facial affectivity is to be expected in normal healthy interactions (Merten \& Krause, 2003). The interactants show many different affects, both negative and positive. Interaction partners adapt to each others' facial affective expressions and respond to their partners' contributions in the inter-subjective space. They adjust their facial 
behaviour to what is discussed and communicated and are what Stern (2000) refers to as, engaged in affect attunement. The participants in an interaction read each other and correspond accordingly. However, this fails in schizophrenia. These patients appear to show roughly the same affect, i.e. either disgust or contempt, throughout the entire interaction. They appear unable to read the other person's contributions and facial expressions and fail to respond accordingly.

We can only speculate about the reasons for this behaviour in patients with schizophrenia. The capacity for engagement in social interaction is first manifested at the level of affective sharing (Lyons-Ruth, 2006). Hobson (2002) assigns the origin of inter-subjective forms of thought to primary forms of emotional relatedness that is evident at the beginning of life. Research in neuroscience has shown that there is an evolutionary preparedness of the infant brain to engage in finely-tuned face-to-face affective communication from birth (Tzourio-Mazoyer et al., 2002). However, the interaction with the caregivers is important for developing this readiness for affective communication as well as the capacity for affect attunement (Schore, 2002). Perhaps the patient's problem as an adult in handling affective communication is a reflection of dysfunctional patterns in the patient's early interactions.

Mirror neurons (Rizzolatti et al., 2002) are important to the process of reading others' minds, as they enable us to read communicative behaviour, feel what they feel and to mirror the affective content that the other person conveys (Trevarthen, 2004). Autism seems to be connected to a deficit in mirror neuron areas (Iacoboni \& Mazziotta, 2007; Williams, Whiten, Suddendorf \& Perrett, 2001). Autistic patients are characterized by their inability to read another person's mind and to understand another's 
motives. Recent research implies that patients diagnosed with schizophrenia may have similar limitations regarding the mirror neurons system (Enticott et al., 2008). This may contribute to difficulties regarding the capacity to read and adapt to another's nonverbal affective behaviour.

What is more, the present studies show that a patient's negative emotional state is actually displayed to the interviewer. Previous research in a nonclinical setting found that patients seemed to try to keep their negative facial affectivity to themselves, as if they were avoiding displays of negative affects during mutual gaze in situations where the interaction partner would be able to read the patient's facial expressions (Merten, 1997). However, patients in a clinical setting in the present studies showed their negative facial affectivity openly during mutual gaze, and the participants overall engaged in more mutual gazing. It seems as if the patients might actually have intended to share these emotions. This highlights the importance of the interaction partner's response to these negative emotions.

The emotions of disgust and contempt are probably not as pleasant to feel as positive emotions. Therefore the interaction partner may want to avoid them. However, this is suboptimal in a clinical situation. Stern (2004) describes the importance of sharing feelings in order to establish a meeting while interacting. He even calls the meeting a "shared feeling voyage". The first study of this research project found that the interviewer's willingness to share and explore the emotional content in the interview was crucial to well functioning communication. This indicates how important it may be in a clinical situation for the professional to pay attention to emotional states evoked by the interview and not avoid emotions, even the negative. 
One successful strategy an interviewer may use to handle negative emotions is to show affects complementary to the patient's (Anstadt et al., 1997; Merten et al., 1996). This may re-establish variability in the emotional interplay. However, affective interaction is a subtle process not consciously steered. Ekman (1997) claims that facial affective expressions are involuntary. Therefore, showing specific affects should not be performed mechanically, as this would jeopardize spontaneity and genuineness in the interaction.

Ekman (1997) maintains that facial emotional expressions are neither intentional nor always meant to send a message to the receiver. In psychoanalytically inspired research (Merten, 1996; Merten \& Krause, 2003; Steimer-Krause, 1996), negative affective expressions in patients with schizophrenia have been suggested as expressions of projective identification (Klein, 1946/1993). Patients may be acting out and involving the interaction partner in unconscious patterns of inter-subjective relating that stem from the patients' past relationships (Merten, 1996; Merten \& Krause, 2003; Steimer-Krause, 1996). Alternatively, negative facial affective expressions in these patients may serve as a way to maintain distance to the interaction partner, with the patient assumed to have a tendency toward emotional detachment from other people (Krause, Steimer, Sänger-Alt \& Wagner, 1989).

\section{Clinical implications}

This dissertation tentatively proposes that negative facial affective expressions in patients with schizophrenia may be a reflection of selfcontempt and self-disgust and may be connected to low self-esteem. Though the present studies may be limited by absence of a marker for 
shame in EMFACS. Shame may be more directly connected to low selfesteem and would thereby potentially serve as a more valid measure for testing this hypothesis. Tomkins (1963) thought that shame was closely connected to both contempt and disgust and could be evoked by the display of those affects. Shame is expressed by blushing in the face, by looking down and lowering the head. Tomkins maintained that shame turn off positive affects and may be triggered by such events as interrupting a joyful activity in the child or by experiencing lack of competence in a situation.

One of Tomkins' (1963) major lines of thought was that emotions of contempt and disgust, if frequently shown, may induce feelings of selfcontempt and self-disgust in the interaction partner. He claimed those feelings are closely connected to humiliation and self-unworthiness. He further claimed that self-contempt and intense feelings of humiliation actually may be present in patients diagnosed with paranoid schizophrenia. He also maintained that people experiencing self-contempt and self-disgust are prone to expose other people for those affects thereby creating a vicious circle of negative emotions. The findings in the present dissertation regarding the presence of disgust and contempt in the facial affective behaviour of patients with schizophrenia seem to be consistent with Tomkins' ideas.

Nathanson (1992) claimed that as the affect of shame undermines selfconfidence and self-esteem it may result in a withdrawal behaviour and isolation from other people. As to psychotherapy, he maintained the importance of the therapist's ability for empathy in order to enter the patient's shame experience, to feel the patient's pain and to gradually pull the patient out of humiliation and of self-disgust. He also wrote: 
"Therapeutic passivity - the decision to remain silent in the face of a humiliated, withdrawn patient - will always magnify shame because it confirms the patient's affect-driven belief that isolation is justified.” (p. 325)

Kohut emphasized the significance of empathy in psychotherapy. Accordingly he claimed the importance of the therapist capacity to respond empathetically to the patient's affective states, expressed by implicit nonverbal communication, such as facial expressions, tone of voice, gestures and postures (Kohut, 1971, 1977, 1984, as cited in Schore, 2002). In interaction with psychotic patients empathetic attunement, expressed through vitality affects, seems to be of significance (Rosenbaum \& Harder, 2007). Schore (2002) also maintained that the therapist should focus on listening to the nonverbal cues and act similarly to a caregiver interacting with an infant; i.e., to respond to and to regulate the nonverbal affective information conveyed by the patient. He stated that the right brain hemisphere is more receptive to processing such information than the verbal left one. He also claimed that affective exchanges in early infancy constitute the very core of the self (Schore, 1994) and are imprinted in the limbic and autonomic nervous system of the infant's right hemisphere brain (Schore, 2001a, 2001b, 2001c). One could therefore speculate whether the self in schizophrenia is engrained by self-disgusting and self-contemptive affective experiences. The connection between affective exchanges, the construction of the self, as well as the experience of self-esteem seem to warrant further investigation.

\section{Validity and generalisability}

One important objective of this research project was to be able to generalise the results to clinical situations for professionals working with 
this group of patients. Therefore, the interviews were performed by psychologists with experience in working with these patients. However, the situation was not identical to a clinical one due to the presence of the cameras. The patients also knew that focus was on communication, although not about the focus on facial expressions and gaze. However, both facial expressions and gaze behaviour are difficult to control. Furthermore, the use of series of interviews may have reduced the risk for bias to some extent as the patients became accustomed to the presence of cameras and may have forgotten the focus on communicative behaviour.

The presence of cameras may have presented a greater potential to influence the results of Study I, since the verbal means of communication included in that study are more open to active manipulation than the nonverbal means otherwise studied. It seems reasonable to assume that the presence of the cameras might induce the patients to restrain their narrations to neutral subjects. However this was not the case. Instead, the patients were very open in sharing their experiences when talking about many difficult and private subjects. On the whole the presence of the cameras did not appear as a serious threat to the reliability of the results.

However, the small number of patients included in Studies II and III does present a limitation. Using a larger sample could have potentially provided evidence for smaller effects of the independent variables. The detailed and time-consuming nature of this type of research and funding limitations made it impossible to include more patients. In order to limit the effect of the small sample, a within-subject design was used. Allowing the patients to be compared to themselves contributed positively to the power of the results. Previous research, using large samples, has shown that negative facial affectivity is specific for this group of patients in comparison to 
healthy subjects. Thereby the inclusion of a healthy-subjects control group in the present studies was not considered necessary. Nonetheless, a healthysubjects control group would have been of interest in determining whether the interviewers adapted their facial affective behaviour to the group at hand. Since no information could be collected about which affects the interviewer would have displayed in interacting with healthy subjects, no such comparisons were possible.

In order to test whether the results in Studies II and III, which used data set 2 , were robust to the change of interviewer, data from data set 1 was used as a comparative material. Because the results from data set 2 implied that facial affectivity and gaze behaviour in the patients was stable throughout an interview series, it was assumed legitimate to restrict the analysis of data set 1 to the first of the three interviews, without jeopardizing validity. This approach was motivated due to a resource shortage preventing the EMFACS and gaze coding of all the data.

The group of patients studied was not a random sample. This raises the question of how representative these patients were for patients diagnosed with schizophrenia as a whole. The cameras themselves may have contributed to a selection bias, as the patients who agreed to participate were probably those most comfortable in the presence of a camera. Accordingly, there may an over-representation of patients with narcissistic personality features. Patients with severe paranoid problems might have felt uncomfortable being videotaped, and thus underrepresented in the sample. Nonetheless the sample was dominated by patients having the diagnosis of paranoid schizophrenia. This skewed representation may diminish the possibility of generalising the results to other schizophrenia subtypes, such as the disorganised or residual types. 
It is important to keep in mind that the sequences analysed in studies II and III were not representative of the content in all clinical situations, but instead featured exceptional experiences, particularly psychotic experiences and other emotionally loaded experiences frequent in clinical situations, but not present in all clinical situations. Thus the results found may be more reliably generalised to interview situations including exceptional experiences narratives. It is also possible that the amount of negative facial affectivity would be lower in sequences with another content. However, speaking against that assumption is previous research pointing at the dominance of negative facial affectivity in these patients during political discussions, as well.

One strength of the present research was the systematic use of co-raters in the qualitative study I. However, their pre-understanding was affected by the fact that all the co-raters were psychologists with psychodynamic training. This may have limited the variability of the interpretations. It would have been interesting from a validity standpoint to include co-raters from a different theoretical context. Nonetheless, during both data collection and during data analysis, self-reflection over the researcher's impact on both data and results was incorporated in accordance with recommendations (Holloway \& Jefferson, 2000; McLeod, 2001; Rennie \& Frommer 2001).

Another strength was the use of independent coders for the EMFACS coding. To avoid bias, the coding was performed by individuals not having participated in the data collection and not having knowledge of the patient's diagnoses, nor the language spoken in the interviews. 
The high standard deviations concerning affects displayed by the patients is potentially problematic. These indicate considerable variation among patients in the frequency of affects. However, when examining the affective expressions for each patient separately, each of the patients clearly displayed either disgust or contempt most frequently. Given that, some patients nonetheless showed a higher overall amount of affects than others, contributing to the high standard deviations. On the other hand, there was a somewhat more moderate variation concerning the distribution of gaze behaviour. While there was still differences between subjects in their gaze distribution (such as the amount of time spent during mutual gaze), on the aggregate level the distribution of gaze behaviour was found to be stable across all the interviews and unaffected by the change of interviewer.

The patients' anti-psychotic medication was another potential concern to the validity of the results. Approximately half of the patients took typical anti-psychotic medication, which may have an impact on the amount of facial expressivity. The other half took atypical anti-psychotic medication, a medication with smaller risk for influencing facial expressivity. However, medication as a factor was not explicitly controlled for, except that most of the patients received the same medication at both data collections. Thus, the medication factor was held constant for most of the patients.

The third study focused on gaze behaviour, which is known to be affected by numerous variables in any interaction. Known factors that influence gaze include differences in socioeconomic status, the interaction distance, gender and age (Pansa-Henderson \& Jones, 1982). In the present studies, status differences were potentially important, as the patients were interviewed by a psychologist and were not talking with a fellow patient or 
a non-professional. Regarding the gender of the interviewers, both were women in their late twenties. Most of the patients were men, and the average age among the patients at the onset of the data collection was 37 years. However, it is hard to evaluate how these factors may have influenced the gaze behaviour in the present studies.

\section{Future research}

A possible next step for future research could be to understand more about the impact of affective exchanges on the experience of the self and selfesteem. One line of research would be to examine whether there may be a connection between negative facial affectivity and low self-esteem in a patient with schizophrenia, as well as examining the significance of affective exchanges in clinical interview situations for improving the patient's self-esteem.

\section{Overall conclusions}

This research project suggests the importance of heeding the emotional interplay in clinical situations with patients diagnosed with schizophrenia in order to achieve well functioning communication. Negative facial affectivity is a dominant and stable feature of the emotional interplay with these patients, as is the patients' intention to impart negative emotions to the interview partner. 


\section{REFERENCES}

Aghevli, M. A., Blanchard, J. J., \& Horan, W. P. (2003). The expression and experience of emotion in schizophrenia: A study of social interactions. Psychiatry Research, 119, 261-270.

Allen, J. G., \& Fonagy P. (2006). Handbook of mentalization-based treatment. West Sussex: Wiley.

Allen, J. G., Fonagy, P., \& Bateman, A. W. (2008). Mentalizing in clinical practice. Arlington, VA: American Psychiatric Publishing.

Allwood, C. M. (1999). Vetenskapsfilosofi och psykologisk forskning. I C. M. Allwood, \& M. G. Erikson (Red.), Vetenskapsteori för psykologi och andra samhällsvetenskaper. Lund: Studentlitteratur.

Allwood, C. M., \& Erikson, M. G. (1999). Vad är vetenskapsteori? I C. M. Allwood, \& M. G. Erikson (Red.), Vetenskapsteori för psykologi och andra samhällsvetenskaper. Lund: Studentlitteratur.

American Psychiatric Association. (1994). Diagnostic and statistical manual of mental disorders. Washington, DC: APA.

Anstadt, T., Merten, J., Ullrich, B., \& Krause, R. (1997). Affective dyadic behaviour, core conflictual relationship themes, and success of treatment. Psychotherapy Research, 7, 397-417.

Barnett, M. A., King, L. M., \& Howard, J. A. (1979). Inducing affect about self or other: Effects on generosity in children. Developmental Psychology, 15, 164-167.

Baron-Cohen, S. (1995). Mindblindness: An essay on autism and theory of mind. Cambridge, MA: MIT Press.

Bavelas, J. B., Coates, L., \& Johnson, T. (2002). Listener responses as a collaborative process: The role of gaze. Journal of Communication, 52, 566-580.

Bent, R., \& Harder, S. (2007). Psychosis and the dynamics of the psychotherapy process. International Review of Psychiatry, 19, 1323.

Berkowitz, L. (1990). On the formation and regulation of anger and aggression: A cognitive-neoassociationistic analysis. American Psychologist, 45, 494-503.

Bleuler, E. (1911). Dementia praecox, or the group of schizophrenias. New York: International Universities Press. 
Bowlby, J. (1973). Attatchment and loss: Vol. 2, Separation and anger. New York: Basic Books.

Büne, M. (2005). “Theory of mind” in schizophrenia: A review of the literature. Schizophrenia Bulletin, 31, 21-42.

Butterworth, G. E., \& Cochran, E. (1980). Towards a mechanism of joint visual attention in human infancy. International Journal of Behavioral Development, 3, 253-272.

Butterworth, G. E., \& Jarret, N. L. M. (1991). What minds have in common is space: Spatial mechanisms for perspective taking in infancy. British Journal of Developmental Psychology, 9, 55-72.

Butterworth, G. E., \& Morissette, P. (1996). Onset of pointing and the acquisition of language in infancy. Journal of Reproductive and Infant Psychology, 14, 219-231.

Cassell, J., McNeill, D., \& McCullough, K-E. (1999). Speech-gesture mismatches: Evidence for one underlying representation of linguistic and nonlinguistic information. Pragmatics \& Cognition, 7, 1-34.

Condon, W. S., \& Ogston, W. D. (1967). A segmentation of behavior. Journal of Psychiatric Research, 5, 221-235.

D’Entremont, B., Hains, S. M. J., \& Muir, D. W. (1997). A demonstration of gaze following in 3 to 6 month olds. Infant Behavior and Development, 20, 569-572.

Darwin, C. (1998/1872). The Expression of the Emotions in Man and Animals. London: Harper Collins.

Dodd, B. (1979). Lip reading in infants: Attention to speech presented inand out-of-synchrony. Cognitive Psychology, 11, 478-484.

Duncan, S., \& Fiske, D. (1977). Face to face interaction. New York: Wiley \& Sons.

Efron, D. (1941). Gestures and environment. New York: King's Crown Press.

Egidius, H. (1997). Natur och kulturs psykologilexikon. Stockholm: Natur och Kultur.

Ekman, P. (1993). Facial expression and emotion. American Psychologist, 48, 384-392.

Ekman, P. (1997). Expression or communication about emotion. In N. L. Segal, G. E. Weisfeld, \& Weisfeld, C. C. (Eds.), Uniting psychology and biology: Integrative perspectives on human development. Washington, DC: American Psychological Association. 
Ekman, P. (2003). Emotions revealed: Understanding faces and feelings. London: Weidenfeld \& Nicolson.

Ekman, P., \& Davidson, R. (1997). The nature of emotion: Fundamental questions. New York: Oxford University Press.

Ekman, P., \& Friesen, W. V. (1969). The repertoire of nonverbal behavior: Categories, origins, usage, and coding. Semiotica, 1, 49-98.

Ekman, P., \& Friesen, W. V. (1978). Manual for the facial action coding system (FACS). Palo Alto, CA: Consulting Psychologists Press.

Ekman, P., Sorenson, E. R., \& Friesen, W. V. (1969). Pan-cultural elements in facial displays of emotion. Science. 164, 86-88.

Elliot, R., Fischer, C. T., \& Rennie, D. L. (1999). Evolving quidelines for publication of qualitative research studies in psychology and related fields. British Journal of Clinical Psychology, 38, 215-229.

Enticott, P. G., Hoy, K. E., Herring, S. E., Johnston, P. J., Daskalakis, Z. J., \& Fitzgerald, P. B. (2008). Reduced motor facilitation during action observation in schizophrenia: A mirror neuron deficit? Schizophrenia Research, 102, 116-121.

Exline, R. V., \& Winters, L. C. (1965). Affective relations and mutual glances in dyads. In S. S. Tomkins \& C. Izards, (Eds.), Affect, cognition and personality. New York: Springer.

Field, T. M. (1994). The effects of mother's physical and emotional unavailability on emotion regulation. Monographs of the Society for Research in Child Development, 59, 208-227.

Fonagy, P., Gergley, G., Jurist E., \& Target, M. (2002). Affect regulation and mentalization: Developmental, clinical and theoretical perspectives. New York: Other Press.

Friesen, W. V., \& Ekman, P. (1984). EMFACS-7. (Unpublished manual)

Frith, U., \& Frith, C. D. (2003). Development and neurophysiology of mentalizing. Philosophical Transactions of The Royal Society of London. Series B, Biological Sciences, 358, 459-473.

Frommer, J., \& Rennie, D. L. (2001). Reflections. In J. Frommer, \& D. L. Rennie (Eds.), Qualitative psychotherapy research methods and methodology. Lengerich: Pabst Science Publishers.

Frosch, S. (2001). On reason, discourse, and fantasy. American Imago, 58, 627-647.

Furuyama, N. (2002). Prolegomena of a theory of between-person coordination of speech and gesture. International Journal of HumanComputer Studies, 57, 347-374. 
Glaser, B. (1978). Theoretical sensitivity. Advances in the methodology of grounded theory. San Fransisco: Sociology Press.

Glaser, B. (1992). Basics of grounded theory analysis. Mill Valley, CA: Sociology Press.

Goldin-Meadow, S. (1998). The development of gesture and speech as an integrated system. In J. M. Iverson, \& S. Goldin-Meadow (Eds.), The nautre and functions of gesture in children's communication. San Francisco: Jossey-Bass Inc. Publishers.

Grant, E. C. (1968). An ethological description of non-verbal behaviour during interviews. British Journal of Medical Psychology, 41, 177184.

Haidt, J., Rozin, P., McCauley, C., \& Imada, S. (1997). Body, psyche, and culture: The relationship between disgust and morality. Psychology and Developing Societies, 9, 107-131

Hill, C. E., Knox, S., Thompson, B. J., Williams, E. N., Hess, S. A., \& Ladany, N. (2005). Consensual qualitative research: An update. Journal of Counseling Psychology, 52, 196-205.

Hobson, P. (2002). The cradle of thought: Exploring the origins of thinking. London: MacMillan.

Hoffman, R. E., Stopek, S., \& Andreasen, N. C. (1986). A comparative study of manic vs. schizophrenic speech disorganization. Archives of General Psychiatry, 43, 831-838.

Holloway, W., \& Jefferson, T. (2000). Doing qualitative research differently. London: Sage.

Hood, B., Willen, J. D., \& Driver, J. (1998). Adult's eyes trigger shifts of visual attention in human infants. Psychological Science, 9, 131-134.

Howell, D. C. (2002). Statistical methods for psychology. Pacific Grove, CA: Duxbury.

Hufnagel, H., Steimer-Krause, E., \& Krause, E. (1991). Mimisches verhalten und erleben bei schizophrenen patienten und bei gesunden. Zeitschrift fur Klinische Psychologie, 20, 356-370.

Iacoboni, M., \& Mazziotta, J. C. (2007). Mirror neuron system: Basic findings and clinical applications. Annals of neurology, 62, 213-218.

Izard, C. E. (1992). Basic emotions, relations among emotions, and emotion-cognition relations. Psychological Review, 99, 561-565.

Izard, C. E. (1994). Innate and universal facial expressions: Evidence from developmental and cross-cultural research. Psychological Bulletin, 115, 288-299. 
Izard, C. E. (2007). Basic emotions, natural kinds, emotion schemas, and a new paradigm. Association for Psychological Science, 2, 260-280.

Izard, C. E., Fantauzzo, C. A., Castle, J. M., Haynes, O. M., Rayias, M. F., \& Putnam, P. H. (1995). The ontogeny and significance of infants' facial expressions in the first 9 months of life. Developmental Psychology, 31, 997-1013.

Karlsson, G. (1995). Psychological qualitative research from a phenomenological perspective. Stockholm: Almqvist \& Wiksell International.

Kendon, A. (1967). Some functions of gaze direction in social interaction. Acta Psychologica, 26, 22-63.

Kendon, A. (1972). Some relationships between body motion and speech. In A. Siegman, \& B. Pope (Eds.), Studies in dyadic communication. New York: Pergamon Press.

Kendon, A. (1980). Gesticulation and speech: Two aspects of the process of utterance. In M. R. Key (Ed.), The relation between verbal and nonverbal communication. The Hague: Mouton

Kendon, A. (1981). Nonverbal communication, interaction and gesture. The Hague: Mouton Publishers.

Kendon, A. (1995). Gestures as illocutionary and discourse structure markers in southern Italian conversation. Journal of Pragmatics, 23, 247-279.

Kita, S., \& Özyürek, A. (2003). What does cross-linguistic variation in semantic coordination of speech and gesture reveal? Evidence for an interface representation of spatial thinking and speaking. Journal of Memory and Language, 48, 16-32.

Klein, M. (1946). Notes on some schizoid mechanisms. International Journal of Psycho-Analysis, 27, 99-110.

Kohut, H. (1971). The analysis of the self. New York: International Universities Press.

Kohut, H. (1977). The restoration of the self. New York: International Universities Press.

Kohut, H. (1984). How does the analysis cure? In A. Goldberg, \& P. Stepansky (Eds.), Chicago: University of Chicago Press.

Krause, R., \& Merten, J. (1999). Affects, regulation of relationship, transference and countertransference. International Forum of Psychonalysis, 8, 103-114. 
Krause, R., Steimer, E., Sänger-Alt, C., \& Wagner, G. (1989). Facial expression of schizophrenic patients and their interaction partners. Psychiatry, 52, 1-12.

Krause, R., Steimer-Krause, E., \& Hufnagel, H. (1992). Expression and experience of affects in paranoid schizophrenia. European Review of Applied Psychology, 42, 131-140.

Kring, A. M., \& Neale, J. M. (1996). Do schizophrenic patients show a disjunctive relationship among expressive, experiential, and psychophysiological components of emotion? Journal of Abnormal Psychology, 105, 249-257.

Kring, A. M., Kerr, S. L., Smith, D. A., \& Neale, J. M. (1993). Flat affect in schizophrenia does not reflect diminished subjective experience of emotion. Journal of Abnormal Psychology, 102, 507-517.

Kring, A. M., \& Earnst, K. S. (1999). Stability of emotional responding in schizophrenia. Behaviour Therapy, 30, 373-388.

Kugiumutzakis, G. (1998). Neonatal imitation in the intersubjective companion in space. In S. Bråten (Ed.), Intersubjective communication and emotion in early ontogeny. Cambridge: Cambridge University Press.

Kvale, S. (1996). InterViews: Introduction to qualitative research interviewing. Thousand Oaks, CA: Sage Publications.

Kvale, S. (2001). The psychoanalytic interview as qualitative research. In J. Frommer, \& D. L. Rennie (Eds.), Qualitative psychotherapy research methods and methodology. Lengerich: Pabst Science Publishers.

Laing, R. D. (1960). The divided self. Harmondsworth: Penguin.

Leahey, T. H. (2002). A history of psychology. Upper Saddle River, NJ: Prentice Hall.

Lyons-Ruth, K. (2006). The interface between attachment and intersubjectivity: Perspective from the longitudinal study of disorganised attachment. Psychoanalytic Inquiry, 26, 595-616

Malterud, K. (2001). Qualitative research: Standards, challenges, and guidelines. The Lancet, 358, 483-488.

Maxwell, J. A. (1996). Qualitative research design. Thousand Oaks: Sage.

McBurney, D. H. (1994). Research methods. Pacific Grove: Brooks-Cole.

McLeod, J. \& Balamoutsou, S. (2001). A method for qualitative narrative analysis of psychotherapy transcripts. In J. Frommer, \& D. L. Rennie (Eds.), Qualitative psychotherapy research methods and methodology. Lengerich: Pabst Science Publishers. 
McLeod, J. (2001). Qualitative research in counselling and psychotherapy. London: Sage.

McNeill, D. (1992). Hand and mind: What gestures reveal about thought. Chicago: The University of Chicago Press.

Meltzer, H. Y. (2003). Antipsychotic and anticholinerg drugs. In M. G. Gelder, J. J. López-Ibor Jr., \& N. C. Andreasen (Eds.), New Oxford textbook of psychiatry. New York: Oxford University Press.

Meltzoff, A. N. (1986). Imitation, intermodal representation and the origins of the mind. In I. B. Lindblom, \& R. Zetterström (Eds.), Precursors of early speech. Wennergren International Symposium Series, 44. Basingtoke: The Macmillian Press.

Merten, J. (1996). Regulation von nähe und distanz in dyadischen interaktionen mit schizophrenen patienten. Gruppenpsychotherapie und Gruppendynamik, 3, 256-273.

Merten, J. (1997). Facial-affective behaviour, mutual gaze, and emotional experience in dyadic interactions. Journal of Nonverbal Behaviour, $21,179-201$.

Merten, J., \& Krause, R. (2003). What makes good therapists fail? In P. Philippot, R. S. Feldman, \& Coats, E. J. (Eds.), Nonverbal behavior in clinical settings. New York: Oxford University Press.

Merten, J., Anstadt, Th., Ullrich, B., Krause, R., \& Buchheim, P. (1996). Emotional experience and facial behavior during the psychotherapeutic process and its relation to treatment outcome: A pilot study. Psychotherapy Research, 6, 198-212.

Morice, R. D., \& Ingram J. C. (1983). Language complexity and age of onset of schizophrenia. Psychological Research, 9, 233-242.

Morice, R. D., \& McNicol, D. (1986). Language changes in schizophrenia: A limited replication. Schizophrenia Bulletin, 12, 239-251.

Morror, S. L. (2005). Quality and trustworthiness in qualitative research in counseling psychology. Journal of counseling psychology, 52, 250260.

Nadel, J., Guérini, C., Pezé, A., \& Rivet, C. (1999). The evolving nature of imitation as a format for communication. In J. Nadel \& G. Butterworth (Eds.), Imitation in Infancy. Cambridge: Cambridge University Press.

Nathanson, D. L. (1992). Shame and pride: Affect, sex and the birth of the self. New York: W.W. Norton \& Company. 
Pansa-Henderson, M., \& Jones, I. H. (1982). Gaze and gaze avoidance as perceived by psychiatrists during clinical interviews with schizophrenic, depressed, and anxious patients. Journal of Nonverbal Behavior, 7, 69-78.

Pizzuto, E., \& Capobianco, M. (2005). The link and differences between deixis and symbols in children's early gestural-vocal system. Gesture, 5, 179-199.

PowerDVD, version 3.0 CyberLink Corp. Retrieved November, 2001, from http://www.gocyberlink.com/english/index.jsp

Poyatos, F. (1993). Paralanguage: A linguistic and interdisciplinary approach to interactive speech and sound. Amsterdam: John Benjamins Publishing.

Poyatos, F. (2002). Nonverbal communication across disciplines: Paralanguage, kinesics, silence, personal and environmental interaction. Amsterdam: John Benjamins Publishing.

Ragin, A. B., \& Oltmanns, T. F. (1986). Lexical cohesion and formal thought disorder during and after psychotic episodes. Journal of Abnormal Psychology, 95, 181-183.

Ragin, A. B., \& Oltmanns, T. F. (1987). Communicability and thought disorder in schizophrenics and other diagnostic groups. A follow-up study. British Journal of Psychiatry, 150, 494-500.

Rennie, D. L., \& Frommer, J. (2001). Reflections. In J. Frommer, \& Rennie D. L. (Eds.), Qualitative psychotherapy research methods and methodology. Lengerich: Pabst Science Publishers.

Ricoeur, P. (1971). The model of the text: Meaningful action considered as a text. Social Research, 38, 529-562.

Riemer, M. D. (1955). Abnormalities of the gaze: A classification. Psychiatric Quarterly, 29, 659-672.

Rizzolatti, G., \& Arbib, M. A. (1998). Language within our grasp. Trends in Neuroscience, 21, 188-194.

Rizzolatti, G., Craighero, L., \& Fadiga, L. (2002). The mirror system in humans. In M. I. Stamenov \& V. Gallese (Eds.) Mirror neurons and the evolution of brain and language. Amsterdam: John Benjamins Publishing Company.

Robson, C. (2002). Real world research: A resource for social scientists and practitioner-researchers. Oxford: Blackwell.

Rozin, P., \& Fallon, A. E. (1987). A perspective on disgust. Psychological Review, 94, 23-41. 
Rutter, D. R. (1978). Visual interaction in schizophrenic patients: The timing of looks. British Journal of Social and Clinical Psychology, 17, 281-282.

Rutter, D. R. (1976). Visual interaction in recently admitted and chronic long-stay schizophrenic patients. British Journal of Social and Clinical Psychology, 15, 295-303.

Rutter, D. R., \& Durkin, K. (1987). Turn-taking in mother-infant interaction: An examination of vocalizations and gaze. Developmental Psychology, 23, 54-61.

Scheflen, A. E. (1963). Communication and regulation in psychotherapy. Psychiatry, 28, 126-136.

Scheflen, A. E. (1964). The significance of posture in communication systems. Psychiatry, 26, 316-331.

Scheflen, A. E. (1978). Susan smiled: On explanation in family therapy. Family Proceedings, 17, 59-68.

Schneider, F., Ellgring, H., Friedrich, J., Fus, I., Beyer, T., Heimann, H., \& Himer, W. (1992). The effects of neuroleptics on facial action in schizophrenic patients. Pharmacopsychiatry, 25, 233-239.

Schore, A. N. (1994). Affect regulation and the origin of the self: The neurobiology of emotional development. Hillsdale, NJ: L. Erlbaum Associates.

Schore, A. N. (2001a). Dysregulation of the right brain: A fundamental mechanism of traumatic attachment and the psychopathogenesis of posttraumatic stress disorder. Australian and New Zealand Journal of Psychiatry, 36, 9-30.

Schore, A. N. (2001b). The effects of early relational trauma on right brain development, affect regulation, and infant mental health. Infant Mental Health Journal, 22, 201-269.

Schore, A. N. (2001c).Effects of a secure attachment relationship on right brain development, affect regulation, and infant mental health. Infant Mental Health Journal, 22, 7-66.

Schore, A. N. (2002). Advances in neuropsychoanalysis, attachment theory, and trauma research: Implications for self psychology. Psychoanalytic Inquiry, 22, 433-484.

Schwab, F., Merten, J., \& Krause, R. (1997). Expressiveness in dyadic communication. In A. Vingerhoets, F. van Bussel, \& Boelhouwer (Eds.), The (non) expression of emotions in health and desease. Tilburg University Press. 
Shadish, R. W., Cook, T. D, \& Campbell, D. T. (2002). Experimental and quasi-experimental design. Boston: Houghton Mifflin.

Steimer-Krause, E. (1996). Transference, affect and relationship. Theory and analysis of nonverbal interactions of schizophrenic patients. Bern, Switzerland: Peter Lang.

Steimer-Krause, E., Krause, R., \& Wagner, G. (1990). Interaction regulations used by schizophrenic and psychosomatic patients: Studies on facial behaviour in dyadic interactions. Psychiatry, 53, 209-228.

Stern, D. N. (2000). The interpersonal world of the infant: A view from psychoanalysis and development psychology. New York: Basic Books.

Stern, D. N. (2004). The present moment in psychotherapy and everyday life. New York: W.W. Norton.

Tomkins, S. S. (1962). Affect imagery consciuousness: Volume I. New York: Springer Publishing Company.

Tomkins, S. S. (1963). Affect imagery consciuousness: Volume II. New York: Springer Publishing Company.

Tomkins, S. S. (1991). Affect imagery consciuousness: Volume III. New York: Springer Publishing Company.

Trémeau, F., Malaspina, D., Duval, F., Corrêa, H., Hager-Budny, M., CoinBariou, L., Macher, J.-P., \& Gorman, J. M. (2005). Facial expressiveness in patients with schizophrenia compared to depressed patients and nonpatient comparison subjects. American Journal of Psychiatry, 162, 92-101.

Trevarthen, C. (1990). Signs before speech. In T. A. Sebeok, \& J. UmikerSebeok (Eds.), Recent developments in theory and history: The semiotic web. Berlin: Mouton de Gruyter.

Trevarthen, C. (1993). The self born in intersubjectivity: The psychology of an infant communicating. In U. Neisser (Ed.), The perceived self. Ecological and interpersonal sources of self-knowledge. Cambridge: Cambridge University Press.

Trevarthen, C. (2004). How infants learn how to mean. In M. Tokoro, \& L. Steels (Eds.), A learning zone of one's own. SONY Future of Learning Series. Amsterdam: IOS Press.

Trevarthen, C., \& Aitken, K. J. (2001). Infant intersubjectivity: Research, theory, and clinical applications. Journal of Child Psychology and Psychiatry, and Allied Disciplines, 42, 3-48. 
Trevarthen, C., \& Marwick, H. (1986). Signs of motivation for speech in infants, and the nature of a mother's support for development of language. In B. Lindblom, \& R. Zetterström (Eds.), Precursors of early speech. Wenner-Gren International Symposium Series, 44. Basingtoke: The Macmillian Press.

Troisi, A., Pasini, A., Bersani, G., di Mauro, M., \& Ciani, N. (1991). Negative symptoms and visual behavior in DSM-III-R prognostic subtypes of schizophreniform disorder. Acta Psychiatrica Scandinavia, 83, 391-394.

Tronick, E. (2007). The neurobehavioral and social emotional development of infants and children. London; Karnac Books.

Tronick, E. (1998). Intervention that effect change in psychotherapy. A model based on infant research. Infant Mental Health Journal, 19, 277-279.

Tzourio-Mazoyer N., De Schonen, S., Crivello, F., Reutter, B., Aujard, Y., \& Mazoyer, B. (2002). Neural correlates of woment face processing by 2-month-old infants. Neuroimage, 15, 454-461.

van Egeren, L., Barratt, M., \& Roach, M. (2001). Mother-infant responsiveness: Timing, mutual regulation and interactional context. Developmental Psychology, 37, 684-697.

Volterra, V. Caselli, C. , Capirci, O., \& Pizzuto, E. (2005). Gesture and the emergence and development of language. In M. Tomasello, \& D. Slobin (Eds.), Beyond nature nurture. Essays in honour of Elizabeth Bates. London: Lawrence Erlbaum Associates Publishers.

Webbink, P. (1986). The power of the eyes. New York: Springer Publishing.

Werbart, A., \& Levander, S. (2005). Understanding the incomprehensible: Private theories of first-episode psychotic patients and their therapist. Bulletin of the Menninger Clinic, 69, 103-136.

Williams, J. H., Whiten, A., Suddendorf, T., \& Perrett, D. I. (2001). Imitation, mirror neurons and autism. Neuroscience and Biobehavioral Reviews, 25, 287-295.

Ödman, P-J. (1994). Interpretation, understanding, knowing: Hermeneutics in theory and practice. Göteborg: Nordstedts. 